\title{
Lipid metabolism and its implications for type 1 diabetes-associated cardiomyopathy
}

\author{
Rebecca H Ritchie1,2, Eser J Zerenturk³, Darnel Prakoso1,4 and Anna C Calkinn',3 \\ ${ }^{1}$ Heart Failure Pharmacology, Baker Heart \& Diabetes Institute, Melbourne, Victoria, Australia \\ ${ }^{2}$ Central Clinical School, Monash University, Melbourne, Victoria, Australia \\ ${ }^{3}$ Lipid Metabolism \& Cardiometabolic Disease Laboratory, Baker Heart \& Diabetes Institute, Melbourne, \\ Victoria, Australia \\ ${ }^{4}$ School of Biosciences, The University of Melbourne, Parkville, Victoria, Australia
}

Correspondence

should be addressed

to R H Ritchie or A C Calkin

Email

rebecca.ritchie@bakeridi.

edu.au or anna.calkin@

bakeridi.edu.au

\begin{abstract}
Diabetic cardiomyopathy was first defined over four decades ago. It was observed in small post-mortem studies of diabetic patients who suffered from concomitant heart failure despite the absence of hypertension, coronary disease or other likely causal factors, as well as in large population studies such as the Framingham Heart Study. Subsequent studies continue to demonstrate an increased incidence of heart failure in the setting of diabetes independent of established risk factors, suggesting direct effects of diabetes on the myocardium. Impairments in glucose metabolism and handling receive the majority of the blame. The role of concomitant impairments in lipid handling, particularly at the level of the myocardium, has however received much less attention. Cardiac lipid accumulation commonly occurs in the setting of type 2 diabetes and has been suggested to play a direct causal role in the development of cardiomyopathy and heart failure in a process termed as cardiac lipotoxicity. Excess lipids promote numerous pathological processes linked to the development of cardiomyopathy, including mitochondrial dysfunction and inflammation. Although somewhat underappreciated, cardiac lipotoxicity also occurs in the setting of type 1 diabetes. This phenomenon is, however, largely understudied in comparison to hyperglycaemia, which has been widely studied in this context. The current review addresses the changes in lipid metabolism occurring in the type 1 diabetic heart and how they are implicated in disease progression. Furthermore, the pathological pathways linked to cardiac lipotoxicity are discussed. Finally, we consider novel approaches for modulating lipid metabolism as a cardioprotective mechanism against cardiomyopathy and heart failure.
\end{abstract}

Journal of Molecular Endocrinology (2017) 58, R225-R240

\section{Introduction}

Diabetic cardiomyopathy is associated with changes in the structure and function of the heart, and thus, is typically characterised by fibrosis and hypertrophy, ultimately resulting in cardiac dysfunction. This phenomenon was first observed in the 1970s after post-mortem studies of four individuals exhibiting concomitant diabetes and heart failure, in the absence of hypertension, coronary artery disease (CAD) or other likely causal factors (Rubler et al. 1972, Regan et al. 1977). Furthermore, the Framingham Heart Study demonstrated that individuals

Published by Bioscientifica Ltd 
with diabetes exhibited a 2.5- to 5-fold increase in the incidence of heart failure, independent of CAD and hypertension (Kannel et al. 1974). Although the concept of diabetic cardiomyopathy is often considered in individuals specifically affected by type 2 diabetes (T2D), a metabolically induced cardiomyopathy, independent of hypertension, nephropathy or ischaemic heart disease is also evident in individuals with type 1 diabetes (T1D) (Gotzsche et al. 1996). Thus, direct pathological effects of diabetes on the myocardium, regardless of aetiology, likely play a causal role in the development of diabetesassociated cardiomyopathy.

Elevated glucose levels, known as hyperglycaemia, are widely considered as a key contributor to the development of metabolic, structural and functional abnormalities observed in the heart in the setting of diabetes (Huynh et al. 2014). Hyperglycaemia results from the inability of hyperinsulinaemia to compensate for insulin resistance, as commonly seen in the setting of T2D. It can also result from insufficient release of insulin from pancreatic betacells (due to their autoimmune destruction), as seen in individuals with T1D. Hyperglycaemia has been shown to promote a variety of pathological pathways linked to the development of cardiac abnormalities (Fang et al. 2004, Boudina \& Abel 2007, Bugger \& Abel 2014, Huynh et al. 2014). These include the accumulation of advanced glycation end products, altered calcium handling, increased reactive oxygen species (ROS) and activation of the renin-angiotensin system (Fiordaliso et al. 2004, Ligeti et al. 2006, Goh \& Cooper 2008, Yao \& Brownlee 2010, Thomas et al. 2013). Indeed, a study of almost 50,000 individuals with diabetes demonstrated that, for each $1 \%$ increase in glycated haemoglobin, there was an $8 \%$ increase in the risk of heart failure (Iribarren et al. 2001). Interestingly, this effect was observed independent of hypertension status, consistent with the finding that diabetic cardiomyopathy can occur in the absence of hypertension as mentioned previously (Rubler et al. 1972, Regan et al. 1977).

A further, but often overlooked, consequence of hyperglycaemia is the modulation of lipid metabolism. Diabetes is associated with impaired myocardial glucose uptake, and thus, there is an increased reliance on fatty acids (FA) as a source of adenosine triphosphate (ATP) in the heart. This effect is potentiated by the presence of dyslipidaemia, which is frequently observed in the setting of diabetes and results in an excess availability of lipids. However, the importance of lipids in the development of diabetic cardiomyopathy has been somewhat underappreciated, particularly in comparison to hyperglycaemia, and forms the basis of this review, as discussed below.

\section{Lipid metabolism and diabetic cardiomyopathy}

As far back as the 1970s, Regan and coworkers demonstrated increased deposition of cholesterol and triglycerides in ventricular autopsy specimens of individuals with diabetes compared to those without (Regan et al. 1977). Intramyocardial lipid overload in failing human hearts has also been shown to be greater in those with diabetes than those free of diabetes (Sharma et al. 2004). Increased myocardial triglyceride accumulation has been associated with increased left ventricular (LV) mass as well as systolic and diastolic dysfunction (Szczepaniak et al. 2003, Rijzewijk et al. 2008). Interestingly, intramyocardial lipid accumulation has even been observed in diabetic individuals prior to the onset of cardiac dysfunction, further implicating a causal role for lipids in the development of cardiomyopathy (McGavock et al. 2007). Cardiac dysfunction due to excess accumulation of lipids, termed as lipotoxic cardiomyopathy or fatty heart, has been an underappreciated clinical entity (Szczepaniak et al. 2007); however, increasing evidence has demonstrated the importance of lipids in the development of diabetic cardiomyopathy and heart failure, as will be discussed. It must be noted that dyslipidaemia, or more specifically, elevated levels of low-density lipoprotein cholesterol and triglycerides and low levels of high-density lipoprotein, are commonly observed in individuals with diabetes (Mahaney et al. 1995, UKPDS33 1998). Indeed, each of these factors has been associated with an increased risk of CAD (Turner et al. 1998). For example, it is well established that oxidised LDL has been shown to drive many pathogenic pathways that contribute to atherosclerotic lesion development (Glass \& Witztum 2001). Therefore, it is likely that the cardiac dysfunction observed in individuals with diabetes is a net result of both CADdriven cardiac dysfunction due to effects of lipids on the vasculature as well as a direct pathological effect of lipids on the myocardium promoting cardiomyopathy (Rubler et al. 1972).

\section{Substrate utilisation}

The heart is flexible in its ability to use different substrates depending upon their availability, as a source of energy to generate ATP, although in the absence of disease, up to $70 \%$ of energy is obtained from the oxidation of

Published by Bioscientifica Ltd. 


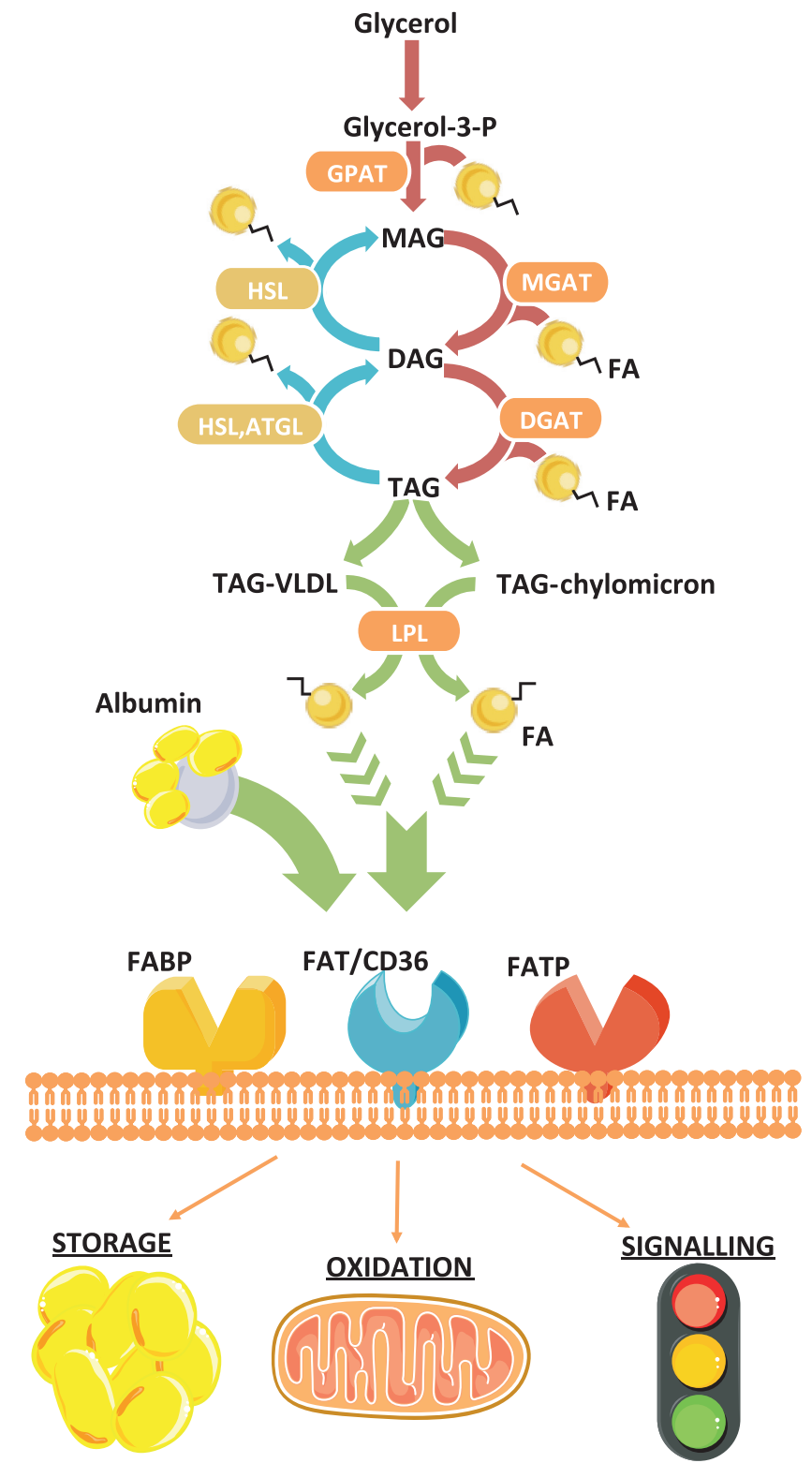

Figure 1

Simplified schema of fatty acid metabolism. ATGL, adipose triglyceride lipase; CD36, cluster of differentiation 36; CGI-58, comparative gene identification 58; DAG, diacylglycerol; DGAT, diacylglycerol acyltransferase; FA, fatty acid; FABP, fatty acid binding protein; FAT, fatty acid translocase; FATP, fatty acid transport protein; GPAT, glycerol-3phosphate acyltransferase; HSL, hormone sensitive lipase; MAG, monoacylglycerol; MGAT, monoacylglycerol acyltransferase; TAG, triacylglycerol; VLDL, very low density lipoprotein.

FAs (Bing et al. 1954, Wisneski et al. 1990). In contrast to the liver, the heart has a limited capacity to carry out de novo synthesis of FAs (Bayeva et al. 2013). Therefore, cardiomyocytes acquire FAs from the circulation or from hydrolysis of stored lipids (Fig. 1). Circulating free FAs bound to albumin can be taken up into cells by transporters such as fatty acid transport protein (FATP) or fatty acid-binding protein. Quantitative studies have, however, determined that facilitated diffusion via cluster of differentiation (CD)36/fatty acid translocase is the major mechanism for FA uptake by cardiomyocytes, contributing up to $70 \%$ of total uptake of FAs (Habets et al. 2007). Interestingly, Glatz and coworkers have demonstrated the feasibility of targeting CD36 to modulate cardiac substrate utilisation in vitro (Glatz et al. 2013), and CD36 has been shown to be necessary for the development of lipotoxic cardiomyopathy in mice (Yang et al. 2007). In humans, CD36 deficiency is associated with reduced myocardial FA uptake (Kusaka et al. 2008). A non-receptor-mediated phenomenon, known as 'flip-flop', in which lipids solubilise within the plasma membrane is also thought to contribute to fatty acid uptake (Kamp et al. 1995). In addition to being transported in the circulation bound to albumin, free FAs can be esterified to form triacylglycerols (TAGs), which are transported in the circulation within lipoproteins as chylomicrons or very-low-density lipoproteins. FAs are subsequently released from these lipoproteins at the surface of capillaries via lipoprotein lipase (LPL). Interestingly, mice overexpressing LPL in a cardiac-specific manner exhibit LV systolic dysfunction accompanied by structural features of cardiomyopathy (Yagyu et al. 2003). Subsequent to their release, FAs are then transported to the mitochondria where they undergo oxidation or are esterified for storage as TAGs for subsequent hydrolysis dependent upon the energy demands of the cell. Beta-oxidation yields acetyl-CoA, which proceeds into the tricarboxylic acid cycle to generate ATP (Bayeva et al. 2013). There is a concomitant activation of pyruvate dehydrogenase kinase (PDK) and inhibition of pyruvate dehydrogenase, which together result in a decrease in glucose oxidation. This allows the heart to 'switch' between energy sources dependent upon availability, a phenomenon described by the Randle principle (Randle et al. 1963). Peroxisome proliferatoractivated receptor (PPAR)-alpha is a master regulator of many of these processes, modulating the expression of genes involved in FA uptake and modification, as well as lipid and glucose oxidation (Burkart et al. 2007). Indeed, overexpression of Ppar-alpha in a cardiac-specific manner mimics much of the changes observed in the setting of diabetes including increased FA oxidation and decreased glucose oxidation, with concomitant cardiac hypertrophy and dysfunction (Finck et al. 2002).

In settings of both T1D and T2D, the heart becomes almost completely reliant upon FAs as a source of energy. Although the mechanisms by which this occurs are

Published by Bioscientifica Ltd 
distinct for the two major types of diabetes as will be discussed below, there is ultimately an increased uptake and utilisation of FAs in both settings. The pathological consequences of this have been extensively reviewed in detail elsewhere (Poornima et al. 2006, Goldberg et al. 2012, Bayeva et al. 2013, Schulze et al. 2016). Thus, we will just briefly address the key pathways by which pathological lipid accumulation is thought to contribute toward the development of cardiomyopathy in the setting of diabetes (Fig. 2).

\section{Pathological effects of lipids in the setting of diabetes}

Lipids and their intermediates are in a constant state of flux, and it is their downstream products, including fatty acyl-CoA, diacylglycerol (DAG) and ceramides, that likely mediate much of the lipotoxic effects. Indeed, these pathological lipid species have been shown to interfere with signalling via modulation of serine/threonine kinases such as protein kinase $\mathrm{C}$, jun $\mathrm{N}$-terminal kinase (JNK), ІкB kinase and mechanistic target of rapamycin, resulting in lipid-induced insulin resistance, as well as promoting inflammation, apoptosis and hypertrophy (Goldberg et al. 2012). The promotion of insulin resistance drives a further increase in insulin levels, which have pathological effects on the heart per se. FAs can also influence contractility as elevated levels of fatty acyl-CoA levels within cardiomyocytes can promote the opening of the $\mathrm{K}_{\text {ATP }}$ channel, which leads to reduced calcium flux (Liu et al. 2001). Intramyocardial lipid accumulation can also promote mitochondrial dysfunction, and in turn, impaired mitochondrial function may further lead to an accumulation of lipotoxic medium-chain acyl carnitines, creating a futile cycle of dysfunction and also promoting ROS production (Koves et al. 2008). These finding are supported by observations in humans, demonstrating that myofibres from right atrial appendages of diabetic individuals exhibited mitochondria that were impaired in their maximal capacity to oxidise FAs and glutamate, with elevated mitochondrial hydrogen peroxide release (Anderson et al. 2009). Finally, FAs can act as ligands for PPAR-alpha, promoting the upregulation of genes involved in FA uptake, transport and oxidation (Burkart et al. 2007). Indeed, Ppar-alpha overexpression in a cardiac-specific manner promotes a phenotype mimicking diabetic cardiomyopathy, thus further promoting the accumulation of lipids and promoting this futile cycle. The lipid-induced upregulation of these key pathological pathways, namely inflammation, increased ROS production, mitochondrial dysfunction, dysregulated insulin signalling, apoptosis and altered calcium handling, have consequent effects to promote contractile dysfunction, impaired cardiac relaxation and fibrosis, ultimately leading to cardiomyopathy. In support of this, individuals with diabetes exhibit cardiac lipid accumulation in association with cardiac hypertrophy and LV systolic and diastolic dysfunction (Szczepaniak et al. 2003, Rijzewijk et al. 2008).

The implications of cardiac lipotoxicity are not limited to cardiomyopathy and can also be detrimental in the setting of myocardial infarction. During ischaemia, the heart is reliant on anaerobic glycolysis to generate ATP. Thus, there is a rapid switch from fat to glucose utilisation. However, the consequence of excess lipid availability is a reciprocal reduction in the utilisation of glucose as a substrate (Randle et al. 1963). Furthermore, impaired insulin signalling, as a result of lipid-induced insulin resistance, also attenuates glucose utilisation. Indeed, individuals with diabetes not only have an increased risk of myocardial infarction, but also have a poorer prognosis (Aronson et al. 1997, Kannel \& McGee 1979, Lehto et al. 1994). Thus, cardiac lipotoxicity has implications for both cardiomyopathy and myocardial infarction. However, further discussion of ischaemia is beyond the scope of this review.

Much of the discussed studies have been performed in the setting of T2D with regard to both rodent studies and studies in humans. In contrast, there is a paucity of information regarding the mechanisms underlying cardiac lipid accumulation in the setting of T1D, and thus, the remainder of this review will focus on cardiomyopathy in the setting of insulin-dependent diabetes.

\section{Type 1 diabetes: changes to lipid metabolism in the human heart}

There are a number of metabolic disturbances in the setting of T1D that are thought to contribute to the cardiomyopathy often seen in these individuals. T1D differs from T2D in that hyperglycaemia occurs much earlier in life and this occurs in the relative absence of hyperinsulinaemia (American Diabetes Association 2009). Due to insulin insufficiency as a result of autoimmune beta-cell destruction, reduced myocardial glucose uptake is observed, and this results in decreased glucose oxidation. As a consequence, the heart becomes heavily reliant on FAs as a source of energy (Herrero et al. 2006). This in itself is thought to promote ROS production, mitochondrial dysfunction and altered calcium handling, contributing to the development of cardiomyopathy often observed

Published by Bioscientifica Ltd. 


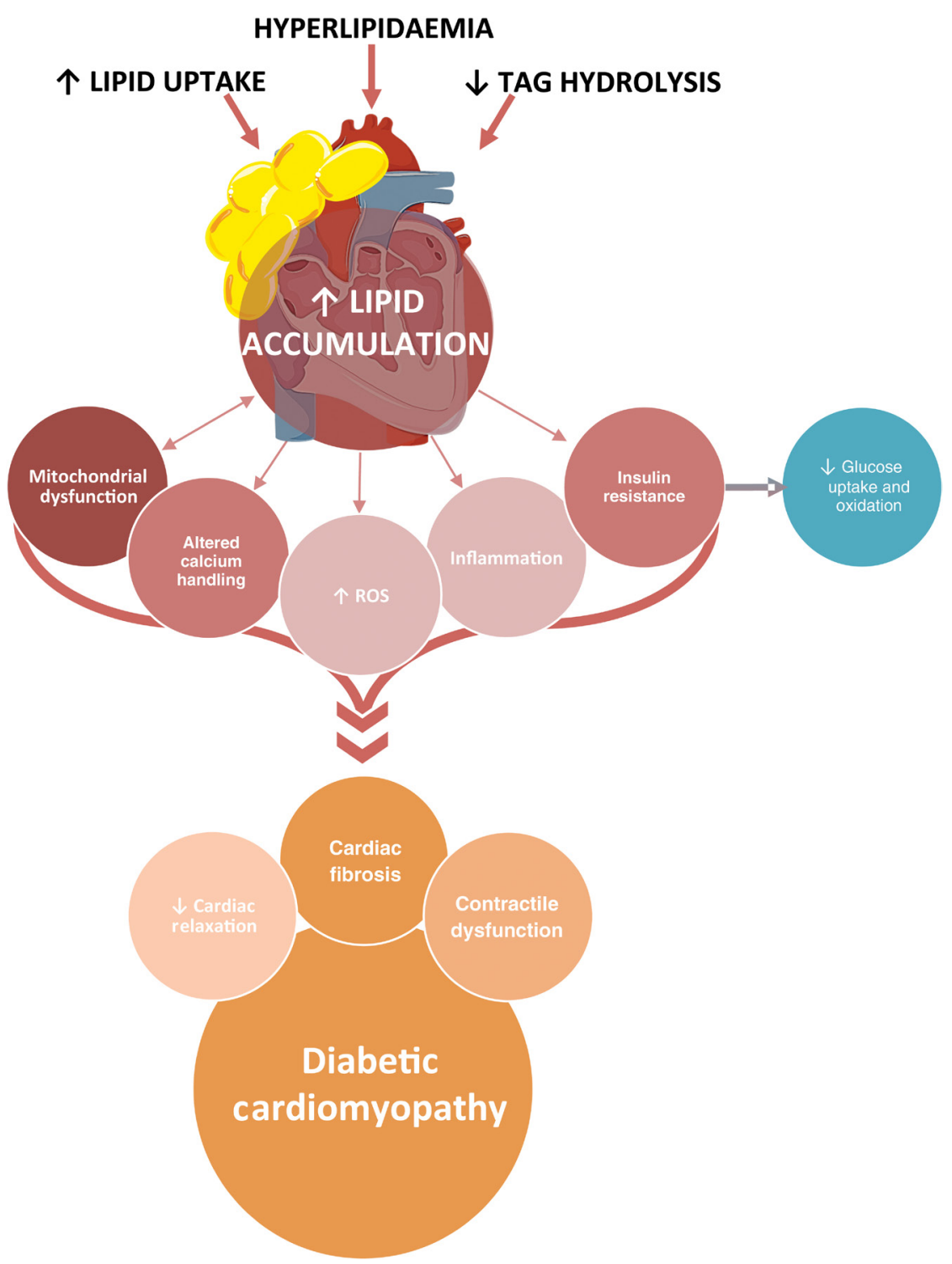

Figure 2

Disturbances in lipid metabolism in the setting of diabetes and their consequential effects on cardiac pathology, structure and function leading to the development of cardiomyopathy. ROS, reactive oxygen species; TAG, triacylglycerols. in these individuals and as discussed previously (Liu et al. 2001, Koves et al. 2008). Furthermore, hyperlipidaemia is often present in individuals with $\mathrm{T} 1 \mathrm{D}$, resulting in increased lipid delivery to the myocardium. This further promotes FA utilisation, oxidation and esterification as well as reduced hydrolysis of triglyceride stores.

Herrero and coworkers specifically sought to assess whether higher dependence on FAs occurred in individuals with T1D by quantitating myocardial glucose and FA metabolism. They demonstrated in young females with T1D that myocardial FA utilisation and oxidation were increased, and myocardial glucose uptake was lower, than non-diabetic individuals, despite hyperglycaemia and elevated plasma FA levels (Herrero et al. 2006). Doria and coworkers assessed myocardial metabolism in individuals with T1D absent of CAD, and also demonstrated that, despite hyperglycaemia, diabetic individuals exhibited reduced myocardial glucose uptake and significantly increased uptake of ketones and FAs (Doria et al. 1991). Furthermore, they demonstrated that net balance of glucose, pyruvate and lactate across the myocardium was inversely related to simultaneous levels of ketone bodies and FAs. These findings on cardiac substrate handling are consistent with the principle of the Randle cycle described previously (Randle et al. 1963). Avogaro and coworkers reported similar findings, and because the observed metabolic abnormalities were normalised by the administration of insulin, which restored glycaemia, they postulated that the metabolic disturbances were a consequence of hypoinsulinaemia and hyperglycaemia 
rather than being the primary defect (Avogaro et al. 1990). Interestingly, using positron emission tomography, Peterson and coworkers demonstrated that fasted T1D subjects with similar glucose and plasma FFA levels to non-diabetic individuals had similar rates of myocardial glucose use and FA oxidation to non-diabetic fasting control subjects, despite higher insulin levels, also indicating the presence of some degree of insulin resistance (Peterson et al. 2008). They also demonstrated that myocardial glucose and FA uptake can be manipulated by altering the plasma environment with regard to hormonal and substrate availability. This emphasises the need to reduce excess FA availability to the heart, highlighting the importance of lipid-lowering therapies in these individuals. This is particularly pertinent in the setting of ischaemia in which there is a predominant requirement for glucose utilisation. Finally, a study by Hammer and coworkers assessed the effects of hyperglycaemia due to $24 \mathrm{~h}$ of partial insulin deprivation in individuals with T1D (Hammer et al. 2008). Plasma FAs increased by 50\%; however, no effect on myocardial triglyceride content or LV diastolic function (as measured by E/A ratio) was observed. The 24-h time frame is likely too short to see changes in TAG content and a longer period of elevated FAs may be required to elicit the true impact on LV function and preclinical models offer utility in this regard.

Whilst studies have identified specific lipid species that accumulate in the hearts of individuals with T2D, no such studies have been performed in humans with T1D, highlighting a clear knowledge gap, at least in humans. However, much information has been gained from mouse models of T1D, and genetic manipulation of key pathways involved in the regulation of lipid metabolism in these models, as discussed below.

\section{Preclinical models of type 1 diabetes-associated cardiomyopathy}

There are a number of mouse models that have been utilised to study diabetic cardiomyopathy in the context of T1D that are generated via either genetic manipulation or chemical induction. The majority of studies focus on three key models, mice treated with the beta-cell toxin, streptozotocin (STZ), the OVE26 mouse and the Akita mouse. The features of each of these models with regard to cardiac pathology are outlined in Table 1, including their advantages and disadvantages. The changes in lipid metabolism observed in each of these models are described below.

\section{Streptozotocin-diabetic mouse}

STZ is a beta-cell toxin that promotes insulinitis via induction of type $\mathrm{C}$ viruses within beta-cells (Rossini et al. 1977). Consequent effects include raised blood glucose levels 5-6 days after administration. Over time, this can develop into overt diabetes dependent upon the susceptibility of the model used. Lipid phenotypes in STZdiabetic mice vary significantly, and this is likely due to differences in the protocol of STZ administration or the background strain of mice. Indeed, studies vary in the age at induction of diabetes, from 6 weeks to 16 weeks of age, as well as the regimen, from a single dose of $185 \mathrm{mg} / \mathrm{kg}$ to 7 doses of $40 \mathrm{mg} / \mathrm{kg}$ (Finck et al. 2002, 2003, Nielsen et al. 2002, Ueno et al. 2008, Pulinilkunnil et al. 2013). Findings in the different models are described below, in descending order from the highest dose of STZ administered.

Pulinilkunnil and coworkers demonstrated that STZinduced diabetes via a single dose of $165-185 \mathrm{mg} / \mathrm{kg}$ was associated with $\sim 4$-fold increase in plasma triglyceride levels (Pulinilkunnil et al. 2013). Significant elevations in cardiac TAG, ceramide and palmitoyl CoA accumulation were observed in these mice, although no change in DAG levels was observed. Concomitant elevations in protein expression of the regulator of TAG hydrolysis, adipose triglyceride lipase (ATGL), as well as PPAR-alpha, perilipin (PLIN)-5 and uncoupling protein (UCP)-3 were observed in the hearts of diabetic mice. Finck and coworkers demonstrated a 2- to 3 -fold upregulation in the expression of key regulators of lipid handling, Pparalpha, acyl-CoA oxidase, carnitine palmitoyl transferase and PPAR gamma co-activator 1 alpha in the hearts of mice rendered diabetic via a single dose of STZ at $180 \mathrm{mg} /$ $\mathrm{kg}$ (Finck et al. 2002). Furthermore, TAG-containing longchain FAs were elevated in the hearts of diabetic mice compared to their non-diabetic counterparts (Finck et al. 2003). Han and coworkers performed lipidomic analysis of cardiac lipids after the induction of diabetes with STZ $(165 \mathrm{mg} / \mathrm{kg}$ ) to 4 -month-old C57BL/6 mice (Han et al. 2007). They particularly focused on cardiolipins, a subclass of phospholipids that are primarily located on the inner mitochondrial membrane and play a role in mitochondrial bioenergetics and apoptosis. A dramatic remodelling of cardiolipin species with STZ diabetes was demonstrated, with some species being depleted within days of the induction of diabetes and others increasing over the duration of diabetes. Thus, these changes appeared to precede changes in mitochondrial morphology or function or TAG accumulation. The authors postulated that these changes in cardiolipins could precipitate mitochondrial

Published by Bioscientifica Ltd 
dysfunction, resulting in the inability of mitochondria to deal with the increased lipid burden seen in the setting of diabetes, namely TAG accumulation (Han et al. 2007). Ueno and coworkers demonstrated that administration of STZ $(150 \mathrm{mg} / \mathrm{kg})$ to 12 - to 16 -week-old C57BL/6 mice until blood glucose readings of $350 \mathrm{mg} / \mathrm{dL}$ were achieved resulted in the presence of lipid droplets in hearts after just 3 weeks of diabetes (Ueno et al. 2008). Plasma TAG levels were increased by $~ 70 \%$ and cardiac TAG and DAG levels were both significantly elevated in diabetic mice. Interestingly, key genes involved in the regulation of lipid uptake, oxidation, FA release, lipolysis and uptake, namely Ppar-alpha, Lpl, Atgl, hormone-sensitive lipase (Hsl) and CD36 were all significantly upregulated in the hearts of diabetic mice. LV interstitial fibrosis and increased collagen deposition were also observed in diabetic mice (Ueno et al. 2008). A similar protocol to render mice diabetic via STZ $(150 \mathrm{mg} / \mathrm{kg})$ in slightly older C57BL/6 mice (10-14 weeks of age) administered every 3-4 days until blood glucose exceeded $350 \mathrm{mg} / \mathrm{dL}$, resulted in a significant elevation in cardiac TAG, DAG, FA and ceramide accumulation, despite no changes in plasma lipid levels (Kuramoto et al. 2014). Consistent with these findings, diabetes was also associated with elevated levels of Cd36, Fatp as well as Plin5, shown to protect lipid droplets from lipolytic attack (Kuramoto et al. 2014). Xu and coworkers demonstrated that a single dose of STZ $(150 \mathrm{mg} / \mathrm{kg})$ to C $57 \mathrm{BL} / 6$ mice was associated with a 2 -fold increase in plasma triglycerides and a 1.5- to 2-fold increase in plasma-free FAs from 3 weeks after STZ administration but did not increase further by 9 weeks of diabetes (Xu et al. 2013). Yan and coworkers rendered C57BL/6 mice diabetic via 6 injections of STZ $(60 \mathrm{mg} / \mathrm{kg})$, resulting in a $\sim 2$-fold increase in plasma triglyceride levels as well as increased cardiac TAG levels and Cd36 mRNA expression by 4-month diabetes duration (Yan et al. 2015). Interestingly, plasma levels of fibroblast growth factor (FGF)-21, known for its role in regulating energy homeostasis, were markedly reduced with the induction of diabetes. Given their role in the modulation of mitochondrial function, which has been shown to be an important mediator of diabetic cardiomyopathy, Novgorodov specifically investigated the effect of cardiac sphingolipid metabolism in mice administered with $50 \mathrm{mg} / \mathrm{kg} \mathrm{STZ}$ for 5 days (Novgorodov et al. 2016). Diabetic mice exhibited increased expression of desaturase 1 , dihydroceramide synthase 2, serine palmitoyl transferase and the rate of ceramide formation by mitochondrial ceramide synthase, indicative of an upregulation of ceramide biosynthesis; however, no changes in ceramide levels were observed, suggesting a compensatory upregulation of ceramide metabolising pathways (Novgorodov et al. 2016). Concomitant mitochondrial defects were observed in these mice. Finally, and in contrast to other studies, Nielsen and coworkers demonstrated no changes in plasma FAs, triglycerides or cholesterol associated with STZ diabetes in C57BL/ 6 mice; however, they did observe $~ 50 \%$ increase in cardiac TAG levels (Nielsen et al. 2002). No changes in other lipids species such as cholesterol, sphingomyelin, phosphatidylcholine or phosphatidylethanolamine were observed in the hearts of these diabetic mice. However, it is possible that changes may have been observed in subspecies that can have functional consequences; however, only total levels were reported for each class. Nielsen and coworkers induced diabetes with a lower dose of STZ ( $40 \mathrm{mg} / \mathrm{kg}$ ) more frequently (7 daily injections), a less toxic and more reproducible approach, which may explain the lack of effect on plasma lipids.

\section{OVE26 RIP-calmodulin mouse}

Epstein and coworkers first described the OVE26 mouse model (Epstein et al. 1989). These mice carry the calmodulin minigene driven by the rat insulin promoter, such that mice exhibit a 5 -fold increase in the content of calmodulin in beta-cells. Calmodulin is a calcium-binding messenger protein, which has been implicated in the control of insulin release from the beta-cell. Subsequent studies in OVE26 mice revealed compromised granule formation and apoptosis of beta-cells that preceded the onset of hyperglycaemia, which occurred as early as 2-3 weeks of age as well as decreased glucose-mediated insulin secretion (Epstein et al. 1992, Yu et al. 2002). Cardiac dysfunction was observed in these mice by 3 months of age. There is limited information regarding the lipid alterations seen in these mice. Studies have reported that OVE26 mice exhibit $\sim 2$-fold increases in plasma FAs and $\sim 3$-fold increase in plasma triglycerides by 5 months of age on an FVB background, which is supported by the findings of others (Liang et al. 2002, Ye et al. 2003, Xu et al. 2013). However, no studies have assessed cardiac lipid levels in this model.

\section{AKITA Ins2+/- mouse}

A more recent mouse model for the study of T1D is the Akita mouse (Yoshioka et al. 1997, Wang et al. 1999). These mice have a single-nucleotide polymorphism in the insulin 2 gene, Ins2, resulting in an amino acid substitution, C96Y. This mutation is associated with

Published by Bioscientifica Ltd 
Table 1 Cardiac features of mouse models of type 1 diabetes.

\section{Unchanged}

(Huynh et al. 2010)

\begin{tabular}{|c|c|}
\hline Model name/parameter & C57BI/6J+STZ \\
\hline \multicolumn{2}{|c|}{ Function } \\
\hline Diastolic function & $\begin{array}{l}\downarrow \text { Decreased (Nielsen et al. } \\
\text { 2002, Westermann et al. } \\
\text { 2009, Pulinilkunnil et al. } \\
\text { 2013, Xu et al. 2013, } \\
\text { Yan et al. 2015, } \\
\text { Novgorodov et al. 2016) }\end{array}$ \\
\hline Systolic function & $\begin{array}{l}\downarrow \text { Decreased (Nielsen et al. } \\
\text { 2002, Westermann et al. } \\
\text { 2009, Pulinilkunnil et al. } \\
\text { 2013, Xu et al. 2013, } \\
\text { Kuramoto et al. 2014, } \\
\text { Novgorodov et al. 2016) }\end{array}$ \\
\hline
\end{tabular}

OVE

VE26

$\downarrow$ Decreased (Zhang et al. 2003, Shen et al. 2004, Ye et al. 2004, Kralik et al. 2005, Xie et al. 2011)

Normal/minor change (Vadvalkar et al. 2013)

Unchanged (Park et al. 2009)

$\downarrow$ Decreased (Zhang et al. $\quad \downarrow$ Decreased (Lu et al. 2007) 2003, Shen et al. 2004,

Ye et al. 2004,

Kralik et al. 2005,

Xie et al. 2011, Xu et al. 2013)

Unchanged/minor change Unchanged (Bugger et al. (Vadvalkar et al. 2013) 2008, Basu et al. 2009, Park et al. 2009, Mishra et al. 2010, LaRocca et al. 2012, Prathipati et al. 2016)

\section{Structure}

Hypertrophy

\section{$\uparrow$ Increased}

(Pulinilkunnil et al. 2013)

Unchanged

(Westermann et al.

2009)

Fibrosis

$\uparrow$ Increased (Ueno et al. 2008, Westermann et al. 2009, Xu et al. 2013,

Kuramoto et al. 2014, Yan et al. 2015)

\section{Substrate metabolism}

Plasma lipids

$\uparrow$ Increased (Ueno et al. 2008, Pulinilkunnil et al. 2013, Xu et al. 2013,

Yan et al. 2015)

Unchanged (Nielsen et al. 2002, Kuramoto et al. 2014)

Cardiac lipids

$\uparrow$ Increased (Nielsen et al. 2002, Han et al. 2007,

Ueno et al. 2008,

Pulinilkunnil et al. 2013,

Kuramoto et al. 2014,

Yan et al. 2015,

Novgorodov et al. 2016)

Glucose oxidation $\downarrow$ Decreased

(Pulinilkunnil et al. 2013)

Fatty acid oxidation $\uparrow$ Increased

(Pulinilkunnil et al. 2013)

\section{Pathways modulated}

Inflammation

$\uparrow$ Increased

(Westermann et al.

2009)

Mitochondrial

Dysfunction/abnormal

function $\uparrow$ Increased

(Huynh et al. 2010)

Wang et al. 2013)

$\uparrow$ Increased

(Huynh et al. 2010)

$\uparrow$ Increased (Li et al. 2011

Wang et al. 2013)

Increased (Chavali et al. 2014)

Unchanged (Bugger et al. 2008, Basu et al. 2009)

Unchanged (Basu et al. 2009)

$\uparrow$ Increased (Liang et al. 2002, Xu et al. 2013)

$\uparrow$ Increased (Bugger et al. 2008)

$\uparrow$ Increased (Bugger et al. 2008, Basu et al. 2009, Pulinilkunnil et al. 2013)

$\uparrow$ Increased (Wang et al. 2013)

Dysfunction/abnormal (Shen et al. 2004, 2006, Ye et al. 2004, Xie et al. 2011, Vadvalkar et al. 2013, Xu et al. 2013) $\uparrow$ Increased (Li et al. 2011, $\downarrow$ Decreased (Bugger et al. 2008, Basu et al. 2009) $\uparrow$ Increased (Bugger et al. 2008, Basu et al. 2009)

$\uparrow$ Increased (Chavali et al. 2014)

Dysfunction/abnormal (Bugger et al. 2008, 2009)
(Pulinilkunnil et al. 2013,

Xu et al. 2013

Novgorodov et al. 2016) http://jme.endocrinology-journals.org DOI: 10.1530/JME-16-0249
C 2017 Society for Endocrinology Printed in Great Britain
Published by Bioscientifica Ltd. 
Table 1 Continued.

\begin{tabular}{|c|c|}
\hline Model name/parameter & C57BI/6J+STZ \\
\hline Apoptosis & $\begin{array}{l}\uparrow \text { Increased (Xu et al. } \\
\text { 2013) }\end{array}$ \\
\hline Oxidative stress & $\begin{array}{l}\uparrow \text { Increased } \\
\text { (Kuramoto et al. 2014, } \\
\text { Westermann et al. 2009, } \\
\text { Xu et al. 2013, Yan et al. } \\
\text { 2015) }\end{array}$ \\
\hline
\end{tabular}

Calcium mobilisation

\begin{tabular}{|c|c|}
\hline FVB/N + STZ & OVE26 \\
\hline $\begin{array}{l}\uparrow \text { Increased } \\
\text { (Wold et al. 2006) }\end{array}$ & $\begin{array}{l}\uparrow \text { Increased (Xie et al. } \\
2011 \text {, Xu et al. 2013) }\end{array}$ \\
\hline $\begin{array}{l}\uparrow \text { Increased } \\
\text { (Wold et al. 2006) }\end{array}$ & $\begin{array}{l}\uparrow \text { Increased (Liang et al. } \\
\text { 2002, Ye et al. 2004, } \\
\text { Song et al. 2007, } \\
\text { Wang et al. 2013, } \\
\text { Xu et al. 2013) }\end{array}$ \\
\hline $\begin{array}{l}\downarrow \text { Decreased } \\
\text { (Wold et al. 2006) }\end{array}$ & $\begin{array}{l}\downarrow \text { Decreased (Ye et al. } \\
\text { 2004, Kralik et al. 2005) }\end{array}$ \\
\hline
\end{tabular}

\begin{tabular}{ll} 
Advantages and disadvantages \\
Advantages & Wide range of STZ \\
& dose allows for easy \\
& manipulation of disease \\
& severity \\
- & High percentage of \\
& successful induction \\
& of diabetes with \\
& low mortality of \\
& experimental animals \\
- Exhibits other & complications of diabetes \\
& - Potential extra- \\
& pancreatic toxic effects, \\
& particularly with high \\
dose STZ & Severity of diabetes can \\
Disadvantages & vary considerably \\
\hline
\end{tabular}

- Potential extrapancreatic toxic effects, particularly with high dose STZ
- Survive $>1$ year, allowing for long-term effects of diabetes to be investigated in the heart

\section{Akita}

Unchanged (Bugger et al. 2008)

$\downarrow$ Decreased (Lu et al. 2007, Bugger et al. 2009, Mishra et al. 2010, LaRocca et al. 2012, Prathipati et al. 2016)

- Onset of T1D at 3-6 weeks similar to humans (15-25 years)

- No confounding effects such as those seen in STZ treatment

- Exhibits other complications of diabetes including retinopathy, neuropathy and nephropathy

- Develop diabetes in the first weeks postpartum, which may influence cardiac development
- Relatively few studies available to assess cardiac phenotype due to recent generation of model impaired folding of proinsulin leading to endoplasmic reticulum (ER) stress in pancreatic islets such that Akita mice exhibit progressive loss of beta-cells, which correlates with diabetes development. Hyperglycaemia is evident from 3 to 4 weeks of age. There are a limited number of studies that have described the lipid phenotype observed in these mice, discussed below.

Basu and coworkers reported elevated levels of palmitoyl CoA, oleoyl CoA and steroyl CoA, ceramides, DAG and TAG in hearts of 3-month-old Akita mice compared to their wild-type counterparts (Basu et al. 2009). Concomitant elevations in PDK4, CD36 and FATP expression were observed as well as an upregulation of palmitate oxidation. No change in glucose oxidation was observed. Lipid droplets were also observed in Akita mice at 3 months of age, and this was more pronounced at 6 months of age at which time an elevation of longchain acyl-CoA dehydrogenase was also observed. These changes were observed in the context of diastolic dysfunction; however, myocardial hypertrophy, fibrosis and systolic dysfunction were absent, highlighting the early stage at which perturbation of lipid metabolism within the heart is evident in this model. Pulinilkunnil and coworkers have also demonstrated a marked elevation in myocardial TAG content in Akita mice (Pulinilkunnil et al. 2013). A concomitant increase in ATGL expression was observed, although this was insufficient to handle the elevated TAG accumulation observed. Elevated levels of serum FAs and triglycerides have also been observed in this model at 24 weeks of age (Bugger et al. 2008). Consistent with the previously mentioned findings, isolated working hearts from Akita mice demonstrated increased palmitate oxidation with a concomitant reduction in glucose oxidation. Despite this, these mice exhibited no change in insulin sensitivity or cardiac efficiency (Bugger et al. 2008). Furthermore, no changes in mitochondrial uncoupling were observed, likely due to the absence of elevated oxidative stress. Further studies by Bugger demonstrated elevated cardiac levels of mitochondrial FA oxidation proteins, consistent with their previous findings of increased cardiac FA oxidation in Akita mice (Bugger et al. 2009). They also demonstrated compromised cardiac mitochondrial function in these mice and suggested that altered mitochondrial membrane lipid content may have contributed to such a phenotype. http://jme.endocrinology-journals.org DOI: 10.1530/JME-16-0249
() 2017 Society for Endocrinology Printed in Great Britain 


\section{Mechanistic insights gained from mouse of models type 1 diabetes}

There are limited studies examining the underlying mechanisms behind the altered lipid metabolism seen in the setting of T1D. However, the use of knockout and transgenic mice to manipulate key regulators of lipid metabolism in the heart in the setting of T1D has generated some understanding of the metabolic defects that contribute to lipotoxic cardiomyopathy.

\section{Cardiac lipid uptake and hydrolysis}

FGF21 is well known for its role in regulating energy homeostasis. Yan and coworkers demonstrated that diabetic Fgf21 KO mice exhibit no difference in plasma lipid levels compared to their wild-type diabetic counterparts(Yanetal.2015); however, these miceexhibited a significant elevation in cardiac lipid accumulation beyond their wild-type diabetic counterparts. They suggested this enhanced lipid accumulation was likely due to nuclear respiratory factor-2-mediated upregulation of CD36 driving the enhanced oxidative stress, cardiac remodelling and ultimately cardiac dysfunction observed in these mice as assessed by increased 3-nitrotyrosine, 4-hydroxynonenal and the marker of fibrosis, connective tissue growth factor. Reduced ejection fraction and fractional shortening were also observed in these mice.

Pulinilkunnil and coworkers studied the effect of modulating Ppar through the use of heterozygous Atgl deletion and cardiac-specific Atgl overexpression. Deletion of just one allele of Atgl was associated with no difference in plasma and cardiac TAG levels, systolic cardiac function, cardiac dilatation in non-diabetic mice; however, diabetic Atgl heterozygous mice exhibited features of diastolic dysfunction, including increased mitral valve deceleration and isovolumetric relaxation time. Partial Atgl deficiency did not have an impact on the diabetes-induced upregulation of Ppar-alpha and its targets, Ucp-3 or Plin5 or accumulation of palmitoyl CoA or ceramides; however, lipid droplets were larger and mitochondrial abnormalities were observed in the hearts of these mice. Conversely, mice overexpressing Atgl in a heart-specific manner via the alpha-myosin heavy-chain (alpha-Mhc) promoter, displayed no difference in plasma TAG levels but were resistant to diabetes-associated myocardial TAG accumulation, lipotoxicity and cardiac dysfunction. Ex vivo studies demonstrated enhanced utilisation of glucose and reduced palmitate oxidation. This shift away from lipid utilisation resulted in reduced accumulation of lipotoxic intermediates such as palmitoyl $\mathrm{CoA}$ and ceramides compared to that seen in wild-type diabetic mice. Concomitant protection from the diabetesassociated decline in LV systolic and diastolic function was observed in these mice, as indicated by measures including mitral valve E-wave velocity, LV volume and isovolumetric relaxation time. Finally, reductions in the diabetes-associated increase in PPAR-alpha, diglyceride acyltransferase-2, CD36, UCP3 and PLIN5 as well as reduced markers of ER stress and mitochondrial complex protein remodelling were observed in alphaMhc-Atgl mice compared to their diabetic counterparts (Pulinilkunnil et al. 2013). These findings provide the rationale for the protection from diabetes-associated cardiac dysfunction seen in these mice.

HSL also plays a role in hydrolysis acting downstream of ATGL to promote the formation of monoacylglycerols from DAGs. Cardiac-specific overexpression of $\mathrm{Hsl}$ (alpha-Mhc-Hsl) rendered mice resistant to diabetesassociated cardiac steatosis and fibrosis (Ueno et al. 2008). Specifically, alpha-Mhc-Hsl mice exhibited no difference in plasma lipid levels; however, they were protected from the diabetes-associated increase in cardiac TAG accumulation, lipid droplet formation and mRNA expression of Ppar-alpha, Gpat and Lpl compared to their wild-type diabetic counterparts. Concomitant reductions in markers of inflammation (nuclear factor kappa-lightchain-enhancer of activated $B$ cells and inducible nitric oxide synthase) and fibrosis (transforming growth factorbeta, matrix metalloproteinase-2, collagen types I, III, IV) and increased antioxidant markers were also observed in alpha-MHC-HSL, highlighting the importance of TAG accumulation in the development of cardiomyopathy.

\section{Altered lipid handling}

Overexpression of human apolipoprotein B in a heartspecific manner in STZ-diabetic mice was not associated with any significant changes in plasma triglycerides, FAs or blood glucose (Nielsen et al. 2002). Despite this, these mice exhibited protection from the $\sim 50 \%$ increase in cardiac TAG accumulation seen with diabetes. Furthermore, cardiac brain natriuretic peptide levels and heart function as assessed by echocardiography were normalised to that seen in non-diabetic mice (Nielsen et al. 2002). These findings highlight the effect of cardiac TAG accumulation on the development of cardiac pathology. Moreover, they emphasise the importance of lipoprotein formation to modulate cardiac lipid metabolism.

Published by Bioscientifica Ltd 
Lipid droplets are a means of storing TAGs and other neutral lipids and perilipins reside at the surface of lipid droplets to prevent hydrolysis from lipases such as ATGL. Remarkably, Plin5-knockout mice lacked detectable lipid droplets in their hearts and exhibited an attenuation of cardiac accumulation of TAG below the level of non-diabetic mice (Kuramoto et al. 2014). Marked reductions in cardiac levels of FAs, DAGs and ceramides were also observed. Diabetic Plin5-deficient mice exhibited a concomitant attenuation of the nicotinamide adenine dinucleotide phosphate (NADPH) oxidase subunits, p47phox, p67phox and the oxidative stress marker, malondialdehyde, as well as the fibrotic marker, collagen 1. Plin 5 deletion also normalised the diabetesassociated attenuation in fractional shortening.

PPAR-alpha drives the transcriptional regulation of lipid uptake and oxidation, and its expression is upregulated in the myocardium of STZ-diabetic mice. Studies led by Kelly and coworkers investigated the importance of PPAR-alpha in the regulation of cardiac lipid regulation through the use of mouse models with cardiac-restricted Ppar-alpha overexpression (alpha-Mhc-Ppar-alpha) or global PPAR-alpha deletion (Finck et al. 2002, 2003). STZ-diabetic Ppar-alpha-null mice did not exhibit the diabetes-associated increase in biventricular/body weight ratio seen in diabetic wild-type mice. Conversely, alpha-Mhc-Ppar-alpha mice exhibited a potentiation of this parameter as well as reduced LV shortening. A concomitant increase in neutral lipid deposition was observed in the hearts of these mice, and mass spectrometry analysis revealed that the most marked increase was in TAG-containing long-chain FAs. The derangements in lipid metabolism, in this case attributed to PPAR-alpha, can have a significant impact on cardiac structure and the development of cardiomyopathy.

\section{Cardiac lipid accumulation and mitochondrial function}

Vadvalkar and coworkers observed metabolic inflexibility in the hearts of OVE26 mice (Vadvalkar et al. 2013). Specifically, they observed large deficits in mitochondrial respiration in response to non-FA substrates. Indeed, the excess availability of FAs seen in the setting of diabetes likely results in incomplete oxidation of FAs which in turn, results in mitochondrial dysfunction and insulin resistance and may promote increased production of ROS (St-Pierre et al. 2002, Koves et al. 2008, Zhang et al. 2010). The interaction between these pathways is highlighted in Fig. 2. Others have demonstrated cardiac mitochondrial dysfunction in the setting of diabetes secondary to modulations of lipid metabolism as described in the abovementioned models (Han et al. 2007, Ueno et al. 2008, Pulinilkunnil et al. 2013). Moreover, modulation of lipid metabolism can restore the mitochondrial dysfunction seen in T1D. This is exemplified by Novgorodov and colleagues who increased lactosylceramide via knockdown of neutral ceramidase (Novgorodov et al. 2016). As mentioned previously, Han and coworkers postulated that early changes in cardiolipin species play a causal role in the mitochondrial dysfunction seen in T1D, which results in an inability of mitochondria to deal with the excess lipid burden in this setting (Han et al. 2007). The role of mitochondrial dysfunction and ROS accumulation in the setting of diabetes warrants further discussion but is beyond the scope of the current review. Nevertheless, reversal of mitochondrial dysfunction or increasing antioxidant levels have both been shown to improve cardiac function in models of T1D (Ye et al. 2003, Shen et al. 2005, 2006, Baseler et al. 2013).

\section{Cardiac lipid accumulation and inflammation}

Dong and coworkers studied the role of toll-like receptor (Tlr)-4 on cardiac lipid accumulation and function utilising non-obese diabetic (NOD) Tlr4 $4^{++}$and NOD Tlr4-/- mice (Dong et al. 2012). NOD mice are a model of autoimmune disease that spontaneously develop diabetes due to autoreactive T lymphocyte infiltration and destruction of pancreatic beta-cells (Makino et al. 1980). They observed no significant differences in plasma triglyceride and FA levels between diabetic NOD Tlr4+/+ and NOD Tlr4 $4^{-/-}$mice. In contrast, cardiac lipid accumulation, as assessed by oil red O-staining, was significantly reduced in Tlr4-null NOD mice up to 3 months after diabetes development, after which no difference was seen between groups. This suggested a role for TLR4 in cardiac lipid accumulation in early diabetes. Concomitant reductions in myeloid differentiation primary response gene 88, p38 mitogenactivated protein kinase (MAPK) and LPL were observed at 1 and 2 months of diabetes. Furthermore, an increase in phosphorylated adenosine monophosphate-activated protein kinase and acetyl-CoA carboxylase as well as an attenuation in phosphorylated JNK were observed in the absence of Tlr4. Diabetes-associated cardiac dysfunction was somewhat ameliorated by the deletion of Tlr4, providing a key link between inflammation, lipid accumulation and their effects on cardiac dysfunction.

Together, these studies demonstrate that cardiac lipid accumulation can occur in the absence of elevated

Published by Bioscientifica Ltd. 
plasma lipid levels in the setting of diabetes, highlighting the importance of disturbances in cardiac metabolism to promote such a phenotype. Moreover, these studies highlight the significance of altered lipid metabolism to the development of diabetic cardiomyopathy, with inflammation, ROS and mitochondrial function all playing roles in this process.

\section{Targeting lipid metabolism as a therapeutic approach to attenuate diabetic cardiomyopathy}

The abovementioned studies emphasise the causal role and impact of disturbances in lipid metabolism on the development of diabetic cardiomyopathy. Moreover, they provide rationale for modulation of lipid pathways to correct the metabolic disturbances seen in the heart in the setting of diabetes and ultimately improve or prevent the cardiac dysfunction seen in this setting.

Considerable research attention has been paid to targeting individual pathological pathways such as ROS accumulation or inflammation in the treatment of cardiomyopathy. As highlighted previously, changes in lipid metabolism are suggested to be upstream of these various pathways. Therefore, targeting lipotoxicity is a particularly attractive therapeutic strategy as it has the potential to mediate beneficial effects on numerous pathways. Many of the abovementioned key regulators of lipid metabolism provide therapeutic potential for the treatment of cardiomyopathy in the setting of diabetes. However, signalling pathways that provide consequential benefit via changes in lipid metabolism also offer promise. For example, previous studies have shown that deletion of MAPK-activated protein kinase-2 (MK2), a downstream mediator of p38 MAPK, has benefits on ischaemiareperfusion and pressure overload-induced hypertrophy (Shiroto et al. 2005, Streicher et al. 2010). In recent findings, Ruiz and coworkers further demonstrated that deletion of $M k 2$ was associated with protection against STZ diabetes-induced cardiomyopathy (Ruiz et al. 2016). Indeed, diabetic $\mathrm{Mk2}^{-/-}$mice did not exhibit the elevated plasma-free FA levels, diastolic dysfunction, increased beta-Mhc/alpha-Mhc ratio, decreased SERCA2a levels or attenuated p38MAPK expression seen in $\mathrm{Mk2}^{+/+}$diabetic mice. However, a reduction in plasma glucose levels and glycated haemoglobin was observed in these mice. Thus, it is difficult to ascertain how much the observed improvements in cardiac function can be attributed to direct effects on the heart or are secondary to systemic alterations due to the global nature of $\mathrm{Mk} 2$ deletion. Furthermore, the relative contribution of lipids to this phenotype is unclear.

Given the heterogeneous nature of lipid metabolism biology throughout the body, it would be anticipated that the most appropriate strategy would be a tissue-specific approach. Gene therapy provides such an approach and is being tested in clinical trials worldwide with over 2000 trials having been completed, underway or approved (http://www.abedia.com/wiley/index.html). This includes viral approaches such as adenovirus making up $21.7 \%$ of studies, retrovirus $(18.3 \%)$ and adeno-associated virus (AAV; 6.7\%) as well as naked/plasmid deoxyribonucleic acid (DNA) (17.4\%). 177 of these studies have been or are targeted at cardiovascular disease.

AAVs provide a particularly attractive strategy, and the first gene therapy approved in the western world was an AAV vector expressing $L p l$, for the treatment of autosomal recessive $L p l$ deficiency (Kaeppel et al. 2013). AAV is a small, human non-pathogenic virus of the parvovirus family and is the only DNA virus that mediates sitespecific integration into the genome (Kotin et al. 1990, Samulski et al. 1991). All viral genes are usually absent in $A A V$ vectors and thus they are unable to integrate into the host genome in either a host genome or random way; yet, they retain their infectious properties (Zacchigna et al. 2014). Their advantages have been reviewed elsewhere (Zacchigna et al. 2014) but include their ability to deliver DNA to post-mitotic tissues for long periods of time, advantageous for targeting the heart. There are currently 10 open trials in phases 1-3 using AAVs for the treatment of cardiovascular disease, with a majority targeting Serca 2 for the treatment of heart failure (http://www.abedia. com/wiley/index.html). Thus, AAVs provide a promising approach for the treatment of lipid derangements in the heart. Moreover, studies defining the importance of disturbances in lipid metabolism to cardiac dysfunction continue to provide a rationale for the use of such therapies as interventions for the treatment of diabetic cardiomyopathy.

\section{Conclusion}

Cardiac lipid accumulation plays an underappreciated but central role in the promotion of key pathological pathways linked to the development of diabetic cardiomyopathy. Studies in rodent models have given insight into the changes in lipid metabolism that lead to the pathological accumulation of lipids in the heart in

Published by Bioscientifica Ltd. 
the setting of T1D; however, limited studies in humans have provided validation of these studies. Indeed, future studies in humans are required to identify key lipid species that accumulate in the T1D heart as well as to validate key pathways involved in this process and the subsequent metabolic disturbances. Nevertheless, studies in preclinical models are critical to the identification, understanding and validation of novel candidates, which have the potential to be targeted for therapeutic intervention in the treatment of diabetic cardiomyopathy.

\section{Declaration of interest}

The authors declare that there is no conflict of interest that could be perceived as prejudicing the impartiality of this review.

\section{Funding}

This work did not receive any specific grant from any funding agency in the public, commercial, or not-for-profit sector.

\section{Acknowledgements}

This work was supported in part by the Victorian Government's Operational Infrastructure Support Program. R H R is supported by a Senior Research Fellowship from the National Health and Medical Research Council of Australia (1059960). E J Z is supported by a National Heart Foundation of Australia Post-doctoral Fellowship (101275). A C C is supported by a National Heart Foundation of Australia Future Leader Fellowship (100067). Schema created using a modification to an image provided by Servier Medical Art by Servier (http://www.servier.com/Powerpoint-image-bank), licensed under a Creative Commons Attribution 3.0 Unported License (https://creativecommons.org/licenses/by/3.0/).

\section{References}

American Diabetes Association 2009 Diagnosis and classification of diabetes mellitus. Diabetes Care 32 (Supplement 1) S62-S67. (doi:10.2337/dc09-S062)

Anderson EJ, Kypson AP, Rodriguez E, Anderson CA, Lehr EJ \& Neufer PD 2009 Substrate-specific derangements in mitochondrial metabolism and redox balance in the atrium of the type 2 diabetic human heart. Journal of the American College of Cardiology $\mathbf{5 4}$ 1891-1898. (doi:10.1016/j.jacc.2009.07.031)

Aronson D, Rayfield EJ \& Chesebro JH 1997 Mechanisms determining course and outcome of diabetic patients who have had acute myocardial infarction. Annals of Internal Medicine 126 296-306. (doi:10.7326/0003-4819-126-4-199702150-00006)

Avogaro A, Nosadini R, Doria A, Fioretto P, Velussi M, Vigorito C, Saccà L, Toffolo G, Cobelli C \& Trevisan R 1990 Myocardial metabolism in insulin-deficient diabetic humans without coronary artery disease. American Journal of Physiology $\mathbf{2 5 8} 18$.

Baseler WA, Dabkowski ER, Jagannathan R, Thapa D, Nichols CE, Shepherd DL, Croston TL, Powell M, Razunguzwa TT, Lewis SE, et al. 2013 Reversal of mitochondrial proteomic loss in Type 1 diabetic heart with overexpression of phospholipid hydroperoxide glutathione peroxidase. American Journal of Physiology: Regulatory, Integrative and Comparative Physiology $\mathbf{3 0 4} 65$
Basu R, Oudit GY, Wang X, Zhang L, Ussher JR, Lopaschuk GD \& Kassiri Z 2009 Type 1 diabetic cardiomyopathy in the Akita (Ins2WT/C96Y) mouse model is characterized by lipotoxicity and diastolic dysfunction with preserved systolic function. American Journal of Physiology: Heart and Circulatory Physiology 297108

Bayeva M, Sawicki KT \& Ardehali H 2013 Taking diabetes to heart deregulation of myocardial lipid metabolism in diabetic cardiomyopathy. Journal of the American Heart Association 2 e000433. (doi:10.1161/JAHA.113.000433)

Bing RJ, Siegel A, Ungar I \& Gilbert M 1954 Metabolism of the human heart. II. Studies on fat, ketone and amino acid metabolism. American Journal of Medicine 16 504-515. (doi:10.1016/00029343(54)90365-4)

Boudina S \& Abel ED 2007 Diabetic cardiomyopathy revisited. Circulation 115 3213-3223. (doi:10.1161/CIRCULATIONAHA. 106.679597)

Bugger H \& Abel ED 2014 Molecular mechanisms of diabetic cardiomyopathy. Diabetologia 57 660-671. (doi:10.1007/s00125-0143171-6)

Bugger H, Boudina S, Hu XX, Tuinei J, Zaha VG, Theobald HA, Yun UJ, McQueen AP, Wayment B, Litwin SE, et al. 2008 Type 1 diabetic akita mouse hearts are insulin sensitive but manifest structurally abnormal mitochondria that remain coupled despite increased uncoupling protein 3. Diabetes 57 2924-2932. (doi:10.2337/db080079)

Bugger H, Chen D, Riehle C, Soto J, Theobald HA, Hu XX, Ganesan B, Weimer BC \& Abel ED 2009 Tissue-specific remodeling of the mitochondrial proteome in type 1 diabetic akita mice. Diabetes $\mathbf{5 8}$ 1986-1997. (doi:10.2337/db09-0259)

Burkart EM, Sambandam N, Han X, Gross RW, Courtois M, Gierasch CM, Shoghi K, Welch MJ \& Kelly DP 2007 Nuclear receptors PPARbeta/delta and PPARalpha direct distinct metabolic regulatory programs in the mouse heart. Journal of Clinical Investigation $\mathbf{1 1 7}$ 3930-3939.

Chavali V, Tyagi SC \& Mishra PK 2014 Differential expression of dicer, miRNAs, and inflammatory markers in diabetic Ins2+/- Akita hearts. Cell Biochemistry and Biophysics 68 25-35. (doi:10.1007/s12013-013-9679-4)

Dong B, Qi D, Yang L, Huang Y, Xiao X, Tai N, Wen L \& Wong FS 2012 TLR4 regulates cardiac lipid accumulation and diabetic heart disease in the nonobese diabetic mouse model of type 1 diabetes. American Journal of Physiology: Heart and Circulatory Physiology 30342.

Doria A, Nosadini R, Avogaro A, Fioretto P \& Crepaldi G 1991 Myocardial metabolism in type 1 diabetic patients without coronary artery disease. Diabetic Medicine $\mathbf{8}$ Spec No 7.

Epstein PN, Overbeek PA \& Means AR 1989 Calmodulin-induced earlyonset diabetes in transgenic mice. Cell 58 1067-1073. (doi:10.1016/0092-8674(89)90505-9)

Epstein PN, Ribar TJ, Decker GL, Yaney G \& Means AR 1992 Elevated beta-cell calmodulin produces a unique insulin secretory defect in transgenic mice. Endocrinology 130 1387-1393. (doi:10.1210/ en.130.3.1387)

Fang ZY, Prins JB \& Marwick TH 2004 Diabetic cardiomyopathy: evidence, mechanisms, and therapeutic implications. Endocrine Reviews 25 543-567. (doi:10.1210/er.2003-0012)

Finck BN, Lehman JJ, Leone TC, Welch MJ, Bennett MJ, Kovacs A, Han X, Gross RW, Kozak R, Lopaschuk GD, et al. 2002 The cardiac phenotype induced by PPARalpha overexpression mimics that caused by diabetes mellitus. Journal of Clinical Investigation 109 121-130. (doi:10.1172/JCI0214080)

Finck BN, Han X, Courtois M, Aimond F, Nerbonne JM, Kovacs A, Gross RW \& Kelly DP 2003 A critical role for PPARalpha-mediated lipotoxicity in the pathogenesis of diabetic cardiomyopathy: modulation by dietary fat content. PNAS 100 1226-1231. (doi:10.1073/pnas.0336724100)

Fiordaliso F, Bianchi R, Staszewsky L, Cuccovillo I, Doni M, Laragione T, Salio M, Savino C, Melucci S, Santangelo F, et al. 2004 Antioxidant

Published by Bioscientifica Ltd 
treatment attenuates hyperglycemia-induced cardiomyocyte death in rats. Journal of Molecular and Cellular Cardiology 37 959-968. (doi:10.1016/j.yjmcc.2004.07.008)

Glass CK \& Witztum JL 2001 Atherosclerosis. The road ahead. Cell 104 503-516.

Glatz JF, Angin Y, Steinbusch LK, Schwenk RW \& Luiken JJ 2013 CD36 as a target to prevent cardiac lipotoxicity and insulin resistance. Prostaglandins, Leukotrienes and Essential Fatty Acids 88 71-77. (doi:10.1016/j.plefa.2012.04.009)

Goh SY \& Cooper ME 2008 Clinical review: the role of advanced glycation end products in progression and complications of diabetes. Journal of Clinical Endocrinology and Metabolism 93 1143-1152. (doi:10.1210/jc.2007-1817)

Goldberg IJ, Trent CM \& Schulze PC 2012 Lipid metabolism and toxicity in the heart. Cell Metabolism 15 805-812. (doi:10.1016/j. cmet.2012.04.006)

Gotzsche O, Darwish A, Gotzsche L, Hansen LP \& Sorensen KE 1996 Incipient cardiomyopathy in young insulin-dependent diabetic patients: a seven-year prospective Doppler echocardiographic study. Diabetic Medicine 13 834-840. (doi:10.1002/(SICI)10969136(199609)13:9<834::AID-DIA225>3.0.CO;2-M)

Habets DD, Coumans WA, Voshol PJ, den Boer MA, Febbraio M, Bonen A, Glatz JF \& Luiken JJ 2007 AMPK-mediated increase in myocardial long-chain fatty acid uptake critically depends on sarcolemmal CD36. Biochemical and Biophysical Research Communications $\mathbf{3 5 5}$ 204-210. (doi:10.1016/j.bbrc.2007.01.141)

Hammer S, Jonker JT, Lamb HJ, van der Meer RW, Zondag W, Sepers JM, de Roos A, Smit JW \& Romijn JA 2008 Short-term hyperglycemic dysregulation in patients with type 1 diabetes does not change myocardial triglyceride content or myocardial function. Diabetes Care 31 1613-1614. (doi:10.2337/dc08-0513)

Han X, Yang J, Yang K, Zhao Z, Abendschein DR \& Gross RW 2007 Alterations in myocardial cardiolipin content and composition occur at the very earliest stages of diabetes: a shotgun lipidomics study. Biochemistry 46 6417-6428. (doi:10.1021/bi7004015)

Herrero P, Peterson LR, McGill JB, Matthew S, Lesniak D, Dence C \& Gropler RJ 2006 Increased myocardial fatty acid metabolism in patients with type 1 diabetes mellitus. Journal of the American College of Cardiology 47 598-604. (doi:10.1016/j.jacc.2005.09.030)

Huynh K, McMullen JR, Julius TL, Tan JW, Love JE, Cemerlang N, Kiriazis H, Du XJ \& Ritchie RH 2010 Cardiac-specific IGF-1 receptor transgenic expression protects against cardiac fibrosis and diastolic dysfunction in a mouse model of diabetic cardiomyopathy. Diabetes 59 1512-1520. (doi:10.2337/db09-1456)

Huynh K, Bernardo BC, McMullen JR \& Ritchie RH 2014 Diabetic cardiomyopathy: mechanisms and new treatment strategies targeting antioxidant signaling pathways. Pharmacology and Therapeutics 142 375-415. (doi:10.1016/j.pharmthera.2014.01.003)

Iribarren C, Karter AJ, Go AS, Ferrara A, Liu JY, Sidney S \& Selby JV 2001 Glycemic control and heart failure among adult patients with diabetes. Circulation 103 2668-2673. (doi:10.1161/01.CIR.103.22.2668)

Kaeppel C, Beattie SG, Fronza R, van Logtenstein R, Salmon F, Schmidt S, Wolf S, Nowrouzi A, Glimm H, von Kalle C, et al. 2013 A largely random AAV integration profile after LPLD gene therapy. Nature Medicine 19 889-891. (doi:10.1038/nm.3230)

Kamp F, Zakim D, Zhang F, Noy N \& Hamilton JA 1995 Fatty acid flipflop in phospholipid bilayers is extremely fast. Biochemistry $\mathbf{3 4}$ 11928-11937. (doi:10.1021/bi00037a034)

Kannel WB \& McGee DL 1979 Diabetes and cardiovascular disease. The Framingham study. JAMA 241 2035-2038. (doi:10.1001/ jama.1979.03290450033020)

Kannel WB, Hjortland M \& Castelli WP 1974 Role of diabetes in congestive heart failure: the Framingham study. American Journal of Cardiology 34 29-34. (doi:10.1016/0002-9149(74)90089-7)

Kotin RM, Siniscalco M, Samulski RJ, Zhu XD, Hunter L, Laughlin CA, McLaughlin S, Muzyczka N, Rocchi M \& Berns KI 1990 Site-specific integration by adeno-associated virus. PNAS 87 2211-2215. (doi:10.1073/pnas.87.6.2211)

Koves TR, Ussher JR, Noland RC, Slentz D, Mosedale M, Ilkayeva O, Bain J, Stevens R, Dyck JR, Newgard CB, et al. 2008 Mitochondrial overload and incomplete fatty acid oxidation contribute to skeletal muscle insulin resistance. Cell Metabolism 7 45-56. (doi:10.1016/j. cmet.2007.10.013)

Kralik PM, Ye G, Metreveli NS, Shem X \& Epstein PN 2005 Cardiomyocyte dysfunction in models of type 1 and type 2 diabetes. Cardiovascular Toxicology 5 285-292. (doi:10.1385/CT:5:3:285)

Kuramoto K, Sakai F, Yoshinori N, Nakamura TY, Wakabayashi S, Kojidani T, Haraguchi T, Hirose F \& Osumi T 2014 Deficiency of a lipid droplet protein, perilipin 5, suppresses myocardial lipid accumulation, thereby preventing type 1 diabetes-induced heart malfunction. Molecular and Cellular Biology 34 2721-2731. (doi:10.1128/MCB.00133-14)

Kusaka Y, Sawai T, Ito M, Oka M, Miyazaki S, Tanaka M \& Minami T 2008 Three cases of acute pulmonary thromboembolism diagnosed by transesophageal echocardiography. Masui 57 973-977.

LaRocca TJ, Fabris F, Chen J, Benhayon D, Zhang S, McCollum L, Schecter AD, Cheung JY, Sobie EA, Hajjar RJ, et al. $2012 \mathrm{Na}+/ \mathrm{Ca} 2+$ exchanger-1 protects against systolic failure in the Akitains 2 model of diabetic cardiomyopathy via a CXCR4/NF-kappaB pathway. American Journal of Physiology: Heart and Circulatory Physiology $\mathbf{3 0 3}$ H353-H367. (doi:10.1152/ajpheart.01198.2011)

Lehto S, Pyorala K, Miettinen H, Ronnemaa T, Palomaki P, Tuomilehto J \& Laakso M 1994 Myocardial infarct size and mortality in patients with non-insulin-dependent diabetes mellitus. Journal of Internal Medicine 236 291-297. (doi:10.1111/j.1365-2796.1994.tb00799.x)

Li Y, Ma J, Zhu H, Singh M, Hill D, Greer PA, Arnold JM, Abel ED \& Peng T 2011 Targeted inhibition of calpain reduces myocardial hypertrophy and fibrosis in mouse models of type 1 diabetes. Diabetes 60 2985-2994. (doi:10.2337/db10-1333)

Liang Q, Carlson EC, Donthi RV, Kralik PM, Shen X \& Epstein PN 2002 Overexpression of metallothionein reduces diabetic cardiomyopathy. Diabetes 51 174-181. (doi:10.2337/diabetes.51.1.174)

Ligeti L, Szenczi O, Prestia CM, Szabo C, Horvath K, Marcsek ZL, van Stiphout RG, van Riel NA, Op den Buijs J, Van der Vusse GJ, et al. 2006 Altered calcium handling is an early sign of streptozotocininduced diabetic cardiomyopathy. International Journal of Molecular Medicine 17 1035-1043.

Liu GX, Hanley PJ, Ray J \& Daut J 2001 Long-chain acyl-coenzyme A esters and fatty acids directly link metabolism to K(ATP) channels in the heart. Circulation Research 88 918-924. (doi:10.1161/ hh0901.089881)

Lu Z, Jiang YP, Xu XH, Ballou LM, Cohen IS \& Lin RZ 2007 Decreased L-type Ca2+ current in cardiac myocytes of type 1 diabetic Akita mice due to reduced phosphatidylinositol 3-kinase signaling. Diabetes 56 2780-2789. (doi:10.2337/db06-1629)

Mahaney MC, Blangero J, Comuzzie AG, VandeBerg JL, Stern MP \& MacCluer JW 1995 Plasma HDL cholesterol, triglycerides, and adiposity. A quantitative genetic test of the conjoint trait hypothesis in the San Antonio Family Heart Study. Circulation 92 3240-3248. (doi:10.1161/01.CIR.92.11.3240)

Makino S, Kunimoto K, Muraoka Y, Mizushima Y, Katagiri K \& Tochino Y 1980 Breeding of a non-obese, diabetic strain of mice. Jikken Dobutsu 29 1-13. (doi:10.1538/expanim1978.29.1_1)

McGavock JM, Lingvay I, Zib I, Tillery T, Salas N, Unger R, Levine BD, Raskin P, Victor RG \& Szczepaniak LS 2007 Cardiac steatosis in diabetes mellitus: a 1H-magnetic resonance spectroscopy study. Circulation 116 1170-1175. (doi:10.1161/CIRCULATIONAHA. 106.645614)

Mishra PK, Givvimani S, Metreveli N \& Tyagi SC 2010 Attenuation of beta2-adrenergic receptors and homocysteine metabolic enzymes cause diabetic cardiomyopathy. Biochemical and Biophysical Research Communications 401 175-181. (doi:10.1016/j.bbrc.2010.09.006) http://jme.endocrinology-journals.org

DOI: 10.1530/JME-16-0249
C 2017 Society for Endocrinology Printed in Great Britain 
Nielsen LB, Bartels ED \& Bollano E 2002 Overexpression of apolipoprotein $\mathrm{B}$ in the heart impedes cardiac triglyceride accumulation and development of cardiac dysfunction in diabetic mice. Journal of Biological Chemistry 277 27014-27020. (doi:10.1074/ jbc.M203458200)

Novgorodov SA, Riley CL, Yu J, Keffler JA, Clarke CJ, Van Laer AO, Baicu CF, Zile MR \& Gudz TI 2016 Lactosylceramide contributes to mitochondrial dysfunction in diabetes. Journal of Lipid Research $\mathbf{5 7}$ 546-562. (doi:10.1194/jlr.M060061)

Park HJ, Zhang Y, Du C, Welzig CM, Madias C, Aronovitz MJ, Georgescu SP, Naggar I, Wang B, Kim YB, et al. 2009 Role of SREBP-1 in the development of parasympathetic dysfunction in the hearts of type 1 diabetic Akita mice. Circulation Research 105 287-294. (doi:10.1161/ CIRCRESAHA.109.193995)

Peterson LR, Herrero P, McGill J, Schechtman KB, Kisrieva-Ware Z, Lesniak D \& Gropler RJ 2008 Fatty acids and insulin modulate myocardial substrate metabolism in humans with type 1 diabetes. Diabetes 57 32-40. (doi:10.2337/db07-1199)

Poornima IG, Parikh P \& Shannon RP 2006 Diabetic cardiomyopathy: the search for a unifying hypothesis. Circulation Research 98 596-605. (doi:10.1161/01.RES.0000207406.94146.c2)

Prathipati P, Metreveli N, Nandi SS, Tyagi SC \& Mishra PK 2016 Ablation of matrix metalloproteinase- 9 prevents cardiomyocytes contractile dysfunction in diabetics. Frontiers in Physiology 793.

Pulinilkunnil T, Kienesberger PC, Nagendran J, Waller TJ, Young ME, Kershaw EE, Korbutt G, Haemmerle G, Zechner R \& Dyck JR 2013 Myocardial adipose triglyceride lipase overexpression protects diabetic mice from the development of lipotoxic cardiomyopathy. Diabetes 62 1464-1477. (doi:10.2337/db12-0927)

Randle PJ, Garland PB, Hales CN \& Newsholme EA 1963 The glucose fatty-acid cycle. Its role in insulin sensitivity and the metabolic disturbances of diabetes mellitus. Lancet 1 785-789. (doi:10.1016/ S0140-6736(63)91500-9)

Regan TJ, Lyons MM, Ahmed SS, Levinson GE, Oldewurtel HA, Ahmad MR \& Haider B 1977 Evidence for cardiomyopathy in familial diabetes mellitus. Journal of Clinical Investigation 60 884-899. (doi:10.1172/jci108843)

Rijzewijk LJ, van der Meer RW, Smit JW, Diamant M, Bax JJ, Hammer S, Romijn JA, de Roos A \& Lamb HJ 2008 Myocardial steatosis is an independent predictor of diastolic dysfunction in type 2 diabetes mellitus. Journal of the American College of Cardiology 52 1793-1799. (doi:10.1016/j.jacc.2008.07.062)

Rossini AA, Like AA, Chick WL, Appel MC \& Cahill GF Jr 1977 Studies of streptozotocin-induced insulitis and diabetes. PNAS $\mathbf{7 4}$ 2485-2489. (doi:10.1073/pnas.74.6.2485)

Rubler S, Dlugash J, Yuceoglu YZ, Kumral T, Branwood AW \& Grishman A 1972 New type of cardiomyopathy associated with diabetic glomerulosclerosis. American Journal of Cardiology 30 595-602. (doi:10.1016/0002-9149(72)90595-4)

Ruiz M, Coderre L, Lachance D, Houde V, Martel C, Thompson Legault J, Gillis MA, Bouchard B, Daneault C, Carpentier AC, et al. 2016 MK2 deletion in mice prevents diabetes-induced perturbations in lipid metabolism and cardiac dysfunction. Diabetes 65 381-392. (doi:10.2337/db15-0238)

Samulski RJ, Zhu X, Xiao X, Brook JD, Housman DE, Epstein N \& Hunter LA 1991 Targeted integration of adeno-associated virus (AAV) into human chromosome 19. EMBO Journal 10 3941-3950.

Schulze PC, Drosatos K \& Goldberg IJ 2016 Lipid use and misuse by the heart. Circulation Research 118 1736-1751. (doi:10.1161/ CIRCRESAHA.116.306842)

Sharma S, Adrogue JV, Golfman L, Uray I, Lemm J, Youker K, Noon GP, Frazier OH \& Taegtmeyer H 2004 Intramyocardial lipid accumulation in the failing human heart resembles the lipotoxic rat heart. FASEB Journal 18 1692-1700. (doi:10.1096/fj.04-2263com)

Shen X, Zheng S, Thongboonkerd V, Xu M, Pierce WM, Klein JB \& Epstein PN 2004 Cardiac mitochondrial damage and biogenesis in a chronic model of type 1 diabetes. American Journal of Physiology: Endocrinology and Metabolism 287 905. (doi:10.1152/ ajpendo.00047.2004)

Shen X, Ye G, Metreveli NS \& Epstein PN 2005 Cardiomyocyte defects in diabetic models and protection with cardiac-targeted transgenes. Methods in Molecular Medicine 112 379-388. (doi:10.1385/1-59259. 879-x:379)

Shen X, Zheng S, Metreveli NS \& Epstein PN 2006 Protection of cardiac mitochondria by overexpression of MnSOD reduces diabetic cardiomyopathy. Diabetes 55 798-805. (doi:10.2337/ diabetes.55.03.06.db05-1039)

Shiroto K, Otani H, Yamamoto F, Huang CK, Maulik N \& Das DK 2005 MK2-/- gene knockout mouse hearts carry anti-apoptotic signal and are resistant to ischemia reperfusion injury. Journal of Molecular and Cellular Cardiology 38 93-97. (doi:10.1016/j.yjmcc.2004.10.018)

Song Y, Du Y, Prabhu SD \& Epstein PN 2007 Diabetic cardiomyopathy in OVE26 mice shows mitochondrial ROS production and divergence between in vivo and in vitro contractility. Review of Diabetic Studies 4 159-168. (doi:10.1900/RDS.2007.4.159)

St-Pierre J, Buckingham JA, Roebuck SJ \& Brand MD 2002 Topology of superoxide production from different sites in the mitochondrial electron transport chain. Journal of Biological Chemistry $\mathbf{2 7 7}$ 44784-44790. (doi:10.1074/jbc.M207217200)

Streicher JM, Ren S, Herschman H \& Wang Y 2010 MAPK-activated protein kinase- 2 in cardiac hypertrophy and cyclooxygenase- 2 regulation in heart. Circulation Research 106 1434-1443. (doi:10.1161/CIRCRESAHA.109.213199)

Szczepaniak LS, Dobbins RL, Metzger GJ, Sartoni-D'Ambrosia G, Arbique D, Vongpatanasin W, Unger R \& Victor RG 2003 Myocardial triglycerides and systolic function in humans: in vivo evaluation by localized proton spectroscopy and cardiac imaging. Magnetic Resonance in Medicine 49 417-423. (doi:10.1002/ mrm.10372)

Szczepaniak LS, Victor RG, Orci L \& Unger RH 2007 Forgotten but not gone: the rediscovery of fatty heart, the most common unrecognized disease in America. Circulation Research 101 759-767. (doi:10.1161/ CIRCRESAHA.107.160457)

Thomas CM, Yong QC, Seqqat R, Chandel N, Feldman DL, Baker KM \& Kumar R 2013 Direct renin inhibition prevents cardiac dysfunction in a diabetic mouse model: comparison with an angiotensin receptor antagonist and angiotensin-converting enzyme inhibitor. Clinical Science 124 529-541. (doi:10.1042/CS20120448)

Turner RC, Millns H, Neil HA, Stratton IM, Manley SE, Matthews DR \& Holman RR 1998 Risk factors for coronary artery disease in noninsulin dependent diabetes mellitus: United Kingdom Prospective Diabetes Study (UKPDS: 23). BMJ 316 823-828. (doi:10.1136/ bmj.316.7134.823)

Ueno M, Suzuki J, Zenimaru Y, Takahashi S, Koizumi T, Noriki S, Yamaguchi O, Otsu K, Shen WJ, Kraemer FB, et al. 2008 Cardiac overexpression of hormone-sensitive lipase inhibits myocardial steatosis and fibrosis in streptozotocin diabetic mice. American Journal of Physiology: Endocrinology and Metabolism 294 E1109-E1118. (doi:10.1152/ajpendo.00016.2008)

UKPDS33 1998 Intensive blood-glucose control with sulphonylureas or insulin compared with conventional treatment and risk of complications in patients with type 2 diabetes (UKPDS 33). UK Prospective Diabetes Study (UKPDS) Group. Lancet 352 837-853. (doi:10.1016/S0140-6736(98)07019-6)

Vadvalkar SS, Baily CN, Matsuzaki S, West M, Tesiram YA \& Humphries KM 2013 Metabolic inflexibility and protein lysine acetylation in heart mitochondria of a chronic model of type 1 diabetes. Biochemical Journal 449 253-261. (doi:10.1042/BJ20121038)

Wang J, Takeuchi T, Tanaka S, Kubo SK, Kayo T, Lu D, Takata K, Koizumi A \& Izumi T 1999 A mutation in the insulin 2 gene induces diabetes with severe pancreatic beta-cell dysfunction in the Mody mouse. Journal of Clinical Investigation 103 27-37. (doi:10.1172/JCI4431) 
Wang Y, Sun W, Du B, Miao X, Bai Y, Xin Y, Tan Y, Cui W, Liu B, Cui T, et al. 2013 Therapeutic effect of MG-132 on diabetic cardiomyopathy is associated with its suppression of proteasomal activities: roles of Nrf2 and NF-kappaB. American Journal of Physiology: Heart and Circulatory Physiology 304 H567-H578. (doi:10.1152/ajpheart.00650.2012)

Westermann D, Walther T, Savvatis K, Escher F, Sobirey M, Riad A, Bader M, Schultheiss HP \& Tschope C 2009 Gene deletion of the kinin receptor B1 attenuates cardiac inflammation and fibrosis during the development of experimental diabetic cardiomyopathy. Diabetes $\mathbf{5 8}$ 1373-1381. (doi:10.2337/db08-0329)

Wisneski JA, Stanley WC, Neese RA \& Gertz EW 1990 Effects of acute hyperglycemia on myocardial glycolytic activity in humans. Journal of Clinical Investigation 85 1648-1656. (doi:10.1172/JCI114616)

Wold LE, Ceylan-Isik AF, Fang CX, Yang X, Li SY, Sreejayan N, Privratsky JR \& Ren J 2006 Metallothionein alleviates cardiac dysfunction in streptozotocin-induced diabetes: role of $\mathrm{Ca} 2+$ cycling proteins, NADPH oxidase, poly(ADP-Ribose) polymerase and myosin heavy chain isozyme. Free Radical Biology and Medicine 40 1419-1429. (doi:10.1016/j.freeradbiomed.2005.12.009)

Xie Z, Lau K, Eby B, Lozano P, He C, Pennington B, Li H, Rathi S, Dong $\mathrm{Y}$, Tian R, et al. 2011 Improvement of cardiac functions by chronic metformin treatment is associated with enhanced cardiac autophagy in diabetic OVE26 mice. Diabetes 60 1770-1778. (doi:10.2337/db100351)

Xu X, Kobayashi S, Chen K, Timm D, Volden P, Huang Y, Gulick J, Yue Z, Robbins J, Epstein PN, et al. 2013 Diminished autophagy limits cardiac injury in mouse models of type 1 diabetes. Journal of Biological Chemistry 288 18077-18092. (doi:10.1074/jbc.M113.474650)

Yagyu H, Chen G, Yokoyama M, Hirata K, Augustus A, Kako Y, Seo T, Hu Y, Lutz EP, Merkel M, et al. 2003 Lipoprotein lipase (LpL) on the surface of cardiomyocytes increases lipid uptake and produces a cardiomyopathy. Journal of Clinical Investigation 111 419-426. (doi:10.1172/JCI16751)

Yan X, Chen J, Zhang C, Zhou S, Zhang Z, Chen J, Feng W, Li X \& Tan Y 2015 FGF21 deletion exacerbates diabetic cardiomyopathy by aggravating cardiac lipid accumulation. Journal of Cellular and Molecular Medicine 19 1557-1568. (doi:10.1111/jcmm.12530)
Yang J, Sambandam N, Han X, Gross RW, Courtois M, Kovacs A, Febbraio M, Finck BN \& Kelly DP 2007 CD36 deficiency rescues lipotoxic cardiomyopathy. Circulation Research 100 1208-1217. (doi:10.1161/01.RES.0000264104.25265.b6)

Yao D \& Brownlee M 2010 Hyperglycemia-induced reactive oxygen species increase expression of the receptor for advanced glycation end products (RAGE) and RAGE ligands. Diabetes 59 249-255. (doi:10.2337/db09-0801)

Ye G, Metreveli NS, Ren J \& Epstein PN 2003 Metallothionein prevents diabetes-induced deficits in cardiomyocytes by inhibiting reactive oxygen species production. Diabetes 52 777-783. (doi:10.2337/ diabetes.52.3.777)

Ye G, Metreveli NS, Donthi RV, Xia S, Xu M, Carlson EC \& Epstein PN 2004 Catalase protects cardiomyocyte function in models of type 1 and type 2 diabetes. Diabetes 53 1336-1343. (doi:10.2337/ diabetes.53.5.1336)

Yoshioka M, Kayo T, Ikeda T \& Koizumi A 1997 A novel locus, Mody4, distal to D7Mit189 on chromosome 7 determines early-onset NIDDM in nonobese C57BL/6 (Akita) mutant mice. Diabetes 46 887-894. (doi:10.2337/diab.46.5.887)

Yu W, Niwa T, Miura Y, Horio F, Teradaira S, Ribar TJ, Means AR, Hasegawa Y, Senda T \& Niki I 2002 Calmodulin overexpression causes $\mathrm{Ca}(2+)$-dependent apoptosis of pancreatic beta cells, which can be prevented by inhibition of nitric oxide synthase. Laboratory Investigation 82 1229-1239. (doi:10.1097/01. LAB.0000027921.01548.C5)

Zacchigna S, Zentilin L \& Giacca M 2014 Adeno-associated virus vectors as therapeutic and investigational tools in the cardiovascular system. Circulation Research 114 1827-1846. (doi:10.1161/ CIRCRESAHA.114.302331)

Zhang X, Ye G, Duan J, Chen AF \& Ren J 2003 Influence of gender on intrinsic contractile properties of isolated ventricular myocytes from calmodulin-induced diabetic transgenic mice. Endocrine Research 29 227-236. (doi:10.1081/ERC-120022318)

Zhang L, Keung W, Samokhvalov V, Wang W \& Lopaschuk GD 2010 Role of fatty acid uptake and fatty acid beta-oxidation in mediating insulin resistance in heart and skeletal muscle. Biochimica et Biophysica Acta 1801 1-22. (doi:10.1016/j.bbalip.2009.09.014)

Received in final form 8 March 2017

Accepted 3 April 2017

Accepted Preprint published online 3 April 2017
(C) 2017 Society for Endocrinology Printed in Great Britain 